\title{
Do microensino à vídeo-aula na era digital
}

\section{Microteaching to video classes in the digital age}

\section{Luiza Maria Cezar Carravetta}

Pós-doutora em Televisão (produção, direção e roteiro) pela UCLA, University of California Los Angeles. Professora da Universidade do Vale do Rio dos Sinos, São Leopoldo/RS

<lcarravetta@unisinos.br>

\section{RESUMO}

Este artigo tem como objetivo contribuir para a capacitação dos professores que gravam videoaulas através da utilização de habilidades técnicas de ensino num estúdio de ensino. Para isto, resgata, historicamente, o micro-teaching no Brasil, sugere habilidades técnicas de ensino para videoaulas e transpõe a tecnologia de um estúdio de TV para um estúdio de ensino. São apresentadas, também, sugestões de como o professor enriquece a sua aula, com a utilização de uma mesa do professor, contendo os recursos informatizados de que ele vai utilizar na sua videoaula. São sugeridas habilidades que enriqueçam as telealunas, vídeo-aulas e web-aulas, apresentadas e gravadas num estúdio de ensino.

Palavras-chave: Vídeo-aulas. Estúdio de Ensino. Habilidades técnicas de Ensino.

\begin{abstract}
This paper aims to contribute to teachers' qualification in recording video classes and using technical abilities of teaching in a teaching studio. For this, it rescues historically micro-teaching in Brazil and suggests teaching techniques, applied in video classes from a TV studio in a teaching studio. It also presents a range of suggestions, using knowledge, on how teachers can use teachers' desk, with computerized resources that it will be use in their video class abilities that enrich tele classes, video classes and web classes, presented and recorded in a teaching studio.
\end{abstract}

Keywords: Video Classes. Teaching studio. Teaching Technical Skills.

\section{Um pouco de história}

De acordo com Sant'Anna (1979), a professora Graciema Pacheco da UFRGS, Universidade Federal do Rio Grande do Sul, trouxe de Stanford, Califórnia, Estados Unidos, na década de60, o micro-teaching, com o objetivo de oportunizar práticas simuladoras de conteúdos específicos ou de habilidades técnicas de ensino. A partir do conhecimento do microensino, Sant'Anna (1979), junto com um grupo de professores, organizou um Laboratório de Ensino na PUCRS, Pontifícia Universidade Católica do Rio Grande do Sul, laboratório que existiu por vários anos como referência do microensino no Brasil e que deu origem ao livro Microensino e Habilidades Técnicas do Professor, com adaptações do micro-teaching, pela experiência dos professores brasileiros e para a realidade do ensino no Brasil. 
Na Unisinos, Universidade do Vale do Rio dos Sinos, nos anos 80, microaulas eram gravadas em vídeo, tanto na Universidade como em escolas, para o treinamento e a capacitação dos futuros professores, nas disciplinas de Prática de Ensino. A Universidade ofereceu, por vários anos, uma Especialização em Habilidades Técnicas de Ensino. Este Curso de Pós-Graduação destinava-se aos egressos das mais variadas áreas de ensino e tinha o objetivo de promover a qualificação docente.

Hoje, ainda, há várias experiências, utilizando a metodologia do microensino. No artigo "A atualidade e necessidade do microensino", Custódio (2010), coordenador do LABTED, Laboratório de Tecnologia Educacional da UEL, Universidade Estadual de Londrina, relata o trabalho de capacitação para professores e para quem tem interesse em participar de concursos públicos, com domínio de conteúdo, mas não de didática, tendo como referência o microensino, proposto no livro de Flávia Sant'Anna.

Dona Hila (2009) escreveu um artigo "O microensino como instrumento de formação do professor de Língua Portuguesa", relatando a experiência do uso do microensino para capacitar estes profissionais. Estudos mais recentes apresentam o estudo de aula que, segundo Félix (2010), se originou no Japão, constituindo-se num processo na formação de professores.

O Instituto de Educação da Universidade de Lisboa desenvolveu um projeto de 4 anos, finalizado em 2014, intitulado "Casos Multimédia", no qual aulas de Matemática eram gravadas, para posterior análise na formação inicial de professores. Atualmente, vídeo-aulas e web-aulas são disponibilizadas na Internet, mantendo, na maioria das vezes, o modelo do ensino presencial com o professor explicando na frente de uma lousa e utilizando alguns recursos como desenhos e ilustrações.

Com a expansão dos cursos de Educação a Distância, há a utilização de vídeo-aulas e web-aulas para os mais variados conteúdos, atendendo a diversos objetivos. Desde cursos preparatórios para concursos para o Enem, Exame Nacional do Ensino Médio, para o domínio de idiomas até Graduações a distância, aprovadas pelo MEC, recursos como vídeo-aulas e web-aulas são utilizados. 
O microensino, as habilidades técnicas do professor as tele-aulas, videoaulas e web-aulas

\section{Teleaulas, videoaulas e webaulas}

Neste estudo, é importante estabelecer semelhanças e diferenças entre teleaulas, vídeo-aulas e web-aulas, para, posteriormente, situar a gravação de videoaulas num estúdio de ensino.

Quanto à conceituação, as teleaulas são transmitidas ao vivo, via satélite, podendo ter interação nas salas remotas ou tele-salas ou mesmo em pólos de ensino, quando se trata de EAD. A interatividade poderá ocorrer via MSN, Skype, Hangout ou por outra ferramenta. O sistema da empresa israelense Gilat Communications, por exemplo, prevê teleaulas com interatividade em tempo real, com mediação feita por telefone.

As vídeo-aulas, em princípio, não são transmitidas ao vivo e são gravadas em estúdios de gravação. Para Morin (2009), as vídeo-aulas são gravadas em estúdio para, depois, serem assistidas pelos alunos em ambientes informatizados como nos pólos de EAD, com a orientação de professores e/ou tutores, ou mesmo em qualquer local, conectando-se a um computador.

As web-aulas constituem-se em aulas, disponibilizadas na web, utilizando recursos, tais como material didático impresso, vídeos, áudios, etc., pela Internet. Há vários ambientes virtuais de aprendizagem, softwares livres, como o Moodle, o Blackboard, o Teleduc que possuem recursos pedagógicos que podem ser utilizados através dos próprios programas. Quanto à interatividade, ela pode ser feita através de e-mails (contato individual ou grupos), chats, foruns, blogs, etc.

Quando professores e alunos encontram-se em tempo real, em teleaulas, videoconferências e web conferências, as interfaces são síncronas e a interação é feita por telefone ou em chats, mediados pelo computador. Se os alunos não estiverem em aula com o professor ao mesmo tempo, como nas vídeo-aulas e nas web-aulas, a interface será assíncrona e a mediação interativa será feita por e-mails individuais, grupos de e-mails, chats, fóruns, blogs, etc.

\section{Habilidades técnicas de ensino nas teleaulas, vídeo-aulas e web-aulas}

O presente estudo enfatiza as vídeo-aulas e as web-aulas, mas também será indicativo às teleaulas, quando as mesmas forem destinadas ao processo de ensino e aprendizagem, transmitidas via satélite. $O$ microensino pode se constituir, como instrumento de ensino, verdadeira ferramenta catalizadora, do 
processo reflexivo na formação inicial e na formação continuada dos professores, mas depende das mediações, realizadas pelos professores formadores na condução e avaliação deste instrumento para a formação docente.

Na proposta de San'Anna (1979), são apresentadas nove habilidades técnicas de ensino. São elas: Habilidade de organizar o contexto, de formular perguntas, de variar a situação-estímulo, de conduzir ao fechamento e atingilo, de ilustrar com exemplos, de propiciar feedback, de empregar reforços, de favorecer experiências integradas de aprendizagem, de facilitar a comunicação.

As vídeo-aulas apresentam algumas especificidades, quando realizadas num estúdio de ensino, para serem transmitidas via web ou gravadas para a sua posterior utilização, tendo em vista a capacitação docente, tanto para o ensino semipresencial como em EAD. Para a qualificação docente nas vídeo-aulas, o microensino pode ser utilizado. As habilidades pertinentes a esta proposta de capacitação são: organizar o contexto, formular perguntas, variar a situação de estímulo, conduzir ao fechamento, ilustrar com exemplos, utilizar reforços e facilitar a comunicação.

\section{Organizar o contexto}

De acordo com San'Anna, organizar o contexto (1979, p.19-20) busca "proporcionar situações que estimulem o aluno a predispor-se e a manter uma adequada atitude de trabalho e estabelece elos cognitivos entre as experiências do aluno e entre os diversos momentos do ensino-aprendizagem". Para organizar o contexto, de acordo com Sant'Anna (1979), é preciso estimulação, organização sequencial do conteúdo e conexão entre objetivos e meios.

Estimulação: ser claro e objetivo na apresentação do conteúdo, definir os objetivos a serem alcançados,

Organização sequencial do conteúdo: organizar o conteúdo numa sequência lógica, partir do simples para o complexo, do conhecido para o novo.

Conexão entre objetivos e meios: relacionar objetivos e meios, deixar claro o que vai ser utilizado, destacar os recursos, utilizando TIC (Tecnologias de Informação e de Comunicação).

\section{Formular perguntas}

Saber perguntar significa proporcionar ao aluno refletir sobre o que está sendo trabalhado. Flávia Sant'Anna (1979, p.23) define perguntas de alta categoria como "aquelas que requerem do aluno, fundamentalmente, 
organização de ideias, relacionamento entre conceitos, conexões entre fatos ou ideias, estabelecimento de previsões, explicações, enfim, elaboração mental".

A autora apresenta os seguintes tipos de perguntas:

Perguntas estimuladoras

Perguntas reforçadoras

Perguntas desencadeadoras

Perguntas esclarecedoras

Perguntas divergentes

Perguntas convergentes

\section{Variação de estímulos}

A variação de estímulos proporciona ganchos de atenção com o objetivo de manter o interesse do aluno no conteúdo que está sendo trabalhado. Ela pode ser feita de várias maneiras. Sant'Anna (1979) propõe ao professor mudança no seu comportamento, no uso de canais receptores, estilos de interação e pausa. estímulo:

Para as vídeo-aulas, sugere-se o domínio das seguintes variações de

Linguagem gestual: com gestos expressivos de mãos, cabeça e corpo

Linguagem verbal: com entonação, pontuação, pausa

Movimentos do professor: com direcionamento do olhar na troca de câmeras

Ganchos de atenção: através de pausas, entonação, mudança de recurso

Utilizar recursos variados: imagens, power point com animação, audiocast, videocast, etc.

\section{Conduzir ao fechamento}

A habilidade de conduzir ao fechamento relaciona-se à de organizar o contexto. Sant'Anna (1979, p. 32) diz que o "fechamento cognitivo é buscado, quando os alunos experimentam o fechamento e estabelecem o elo entre o novo conhecimento e o anterior". Para a autora, os alunos tornam-se capazes de reorganizar o seu aprendizado e de perceber o que realmente aprenderam.

Conduzir ao fechamento pode ser feito através de revisão, aplicação e extensão.

Revisão: consolidação de conceitos

Aplicação: utilização dos conceitos, ideias em situações novas

Extensão: relação com conceitos/ideias anteriores ou posteriores 


\section{Ilustrar com exemplos}

A utilização de exemplos ajuda os alunos na compreensão dos conteúdos trabalhados. Sant'Anna (1979, p. 34) diz que: "por meio do exemplo, pode-se conduzir a ideias e pensamentos claros, significativos e bem estruturados". Para as vídeo-aulas, exemplos são importantíssimos e, se aliados à mudança de planos, podem manter a atenção dos alunos, além de esclarecer conceitos que estejam sendo trabalhados.

É bom considerar na ilustração com exemplos:

Exemplos dos simples aos complexos

Exemplos compatíveis com os conceitos/ideias

Conexão exemplo/ideias

\section{Facilitar a comunicação}

O professor é um comunicador. Ele utiliza a comunicação, tanto a verbal como a não verbal, para trabalhar com informações, para estruturar o conteúdo de sua matéria de ensino. Além disso, é através do processo comunicativo que é feita a interatividade com os alunos. A habilidade de facilitar a comunicação torna a videoaula mais eficiente. Como o professor vai dar a aula para uma câmera, sem o retorno imediato da reação dos alunos, ele precisa eleger esta habilidade como prioritária. Muitas ações são semelhantes a uma aula presencial, mas algumas merecem ênfase maior como o direcionamento do olhar, de acordo com a mudança de câmera, por exemplo.

Destacam-se as seguintes formas de comunicação:

Comunicação oral: clara, concisa, coerente, com vocabulário preciso e encadeamento de ideias.

Entonação: enfatizar ideias principais, através da entonação com exclamações, interrogações, reticências, vírgulas e pontos.

Pausas e silêncios: permitir que os alunos pensem através de pequenos momentos de interrupção da comunicação oral.

Expressão corporal: utilizar o corpo, expressões corporais, faciais, gestuais na comunicação de mensagens.

Ganchos de atenção: intercalar conteúdo com recursos, estabelecendo ganchos de atenção. 


\section{O estúdio de ensino}

Para que se compreenda a gravação de videoaulas num Estúdio de Ensino, são fundamentais o conhecimento de um estúdio de TV, suas características e equipamentos que o compõem. Além disso, faz-se necessária a transposição da tecnologia do Estúdio de TV, para o Estúdio de Ensino, resguardando-se as características do primeiro e fundamentando-as no processo de ensinoaprendizagem para a implementação das tecnologias de vídeo e da TV, numa proposta metodológica, norteadora do segundo.

O estúdio de ensino para a gravação de vídeo-aulas possui características semelhantes a um estúdio de TV, ou seja, uma sala grande com pé direito alto, isolada acusticamente, com piso liso, para as câmeras circularem livremente, iluminação adequada, fundo infinito na cor azul ou verde, para o uso de chroma key, câmeras, tripés, microfones, dimmer, etc..

Os elementos essenciais de um estúdio de TV, transpostos para um estúdio de ensino são: cenário, iluminação, câmeras, microfones e central técnica. Além deles, a mesa do professor com computador, monitores, desktop, mesa waikon, lousa digital farão a diferença para a gravação das vídeo-aulas.

\section{Cenário}

O cenário de um estúdio de ensino é constituído de um fundo infinito na cor azul ou verde, para a utilização do chromakey, recurso utilizado para a criação de cenário virtual, e para a projeção de imagens, relacionadas ao conteúdo que está sendo desenvolvido. Quando não for utilizado o cenário virtual, o estúdio deve ter cortinas, tapadeiras e praticáveis para a composição de uma sala de aula e lousa digital para ser usada pelo professor.

\section{lluminação}

A iluminação deve ser constituída de spots com luz fria, para permitir que o professor fique à vontade durante o período em que estiver dando aula. Os cenários virtuais e o chromakey exigem iluminação especial.

\section{Câmeras de vídeo}

No estúdio, há três câmeras de vídeo, sendo uma disponibilizada para a captação da imagem do professor, uma para os planos de detalhe e uma para 
o plano geral, compondo a imagem do professor com os recursos utilizados. As câmeras são usadas para apresentar o professor e fornecer a informação visual de diferentes ângulos, com o objetivo de evitar uma aula estática.

\section{Central técnica}

A central técnica situa-se numa sala separada com a mesa de corte, que será operada por um técnico, o equipamento para a gravação das videoaulas e para a transmissão via web, se este for o objetivo.

\section{Mesa do professor}

O fundo infinito na cor verde, ou azul, é utilizado para os cenários virtuais, ou mesmo, para as ilustrações, selecionadas pelo professor como fundo, de acordo com o conteúdo que está sendo trabalhado na videoaula.

A mesa do professor num estúdio de ensino deve conter um computador com todo o material que será utilizado na aula, mesa waicon, para explicações e gráficos, câmera de mesa e monitores.

Exemplo de mesa do professor num estúdio de ensino

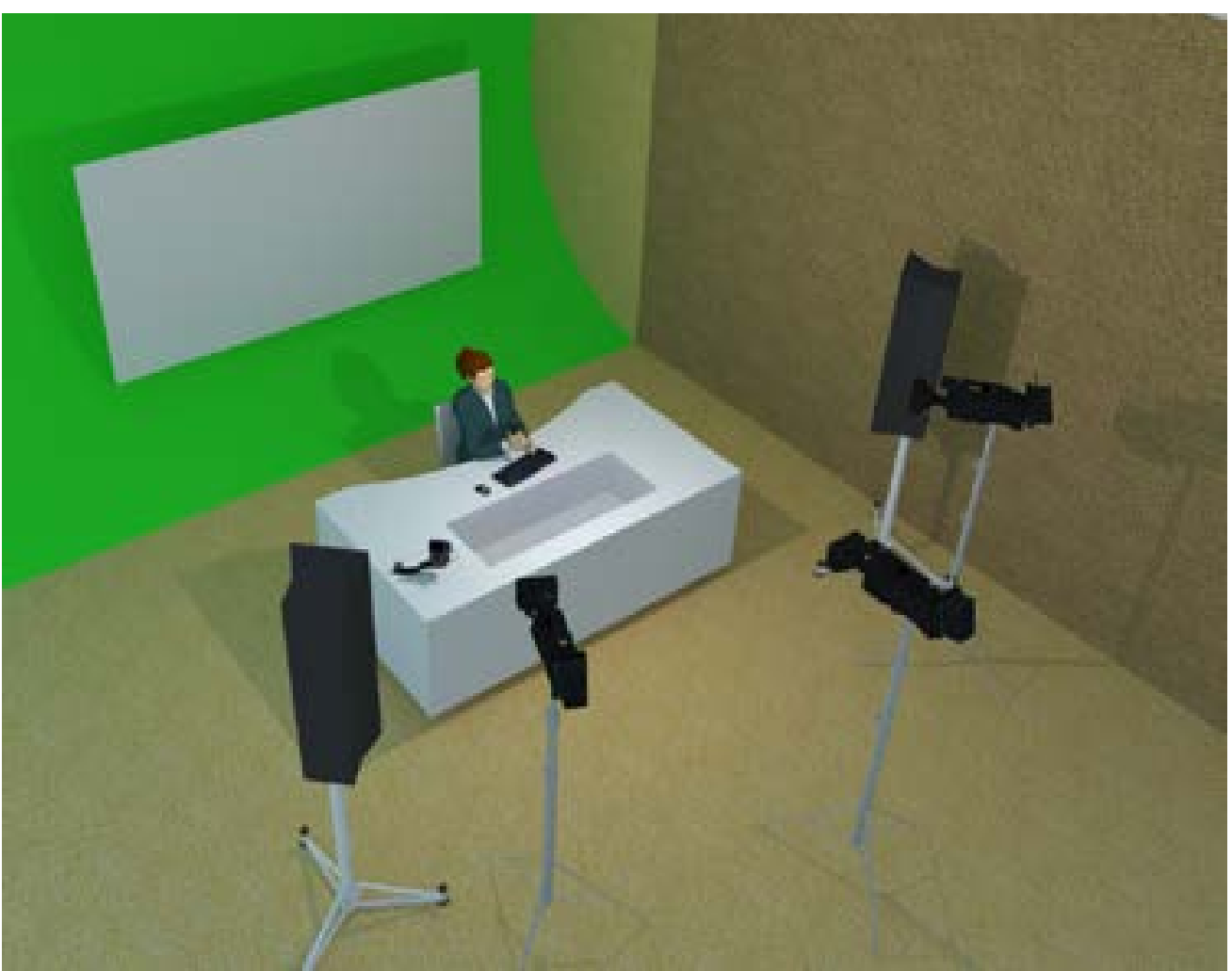




\section{Computador PC}

O computador deve estar inserido na mesa do professor, possibilitando o uso dos aplicativos já instalados, o acesso à Internet a aos recursos instrucionais, selecionados pelo professor para a vídeo-aula. Através do PC da mesa, o professor terá à disposição o material da sua aula e ele mesmo fará a sua inserção no momento certo, tornando a atividade próxima ao que ocorre na aula presencial.

\section{Monitores}

Na mesa do professor, é interessante que haja três monitores embutidos, que servem para transmitir conteúdo do $\mathrm{PC}$, imagem do professor e um monitor máster, que transmite a imagem que está indo ao ar ou sendo gravada. Deste modo, o professor tem o domínio da aula, vendo a imagem do que o aluno está recebendo.

Se o professor quiser dar aula em pé, a mesa pode ser afastada (por isto ela deve ter sistema de rodízio), podendo usar cenário virtual, ou mesmo utilizando a lousa. Neste caso, os recursos podem ser inseridos pela técnica, se a aula estiver sendo transmitida ao vivo pela web ou posteriormente através da edição em aulas gravadas.

\section{Desk Top}

A câmera fixa na mesa, chamada desk top, serve para a captação de recursos, tais como: fotos, gráficos, desenhos e até mesmo esquemas e pequenos textos, elaborados na hora pelo professor na mesa waicon.

\section{Mesa Waicon}

A mesa waicon é uma mesa digitalizadora que funciona como lousa. Ela fica colocada sobre a mesa e o professor poderá fazer esquemas, colocar ilustrações, etc. A gravação capta tudo o que ela contém e o switcher coloca no ar a imagem que o aluno recebe no computador.

\section{Preparação e gravação de vídeo-aulas num estúdio de ensino}

Para que uma aula seja dada num estúdio de ensino, o professor deve prepará-la, especificamente para este fim, tendo o cuidado com as estratégias 
de ensino, bem como com o material instrucional que será utilizado, usando todos os equipamentos e a tecnologia que o estúdio possui.

No estúdio, são colocados e disponibilizados todos os materiais que serão utilizados na aula. Para a colocação do material no estúdio, o professor terá a ajuda de cinegrafistas e de um técnico responsável pela gravação e pelo switcher, fazendo os cortes necessários para colocar no ar a imagem que o aluno vai receber, quer seja do estúdio, quer seja do rack dos equipamentos, como CD player, pendrive etc., quer seja pela web.

Para a orientação aos professores que gravarão as videoaulas, são necessários o apoio pedagógico e o apoio técnico.

\section{Apoio pedagógico}

O apoio pedagógico pode ser feito por uma equipe ou por um pedagogo, destinados à assessoria pedagógica para videoaulas. As principais atividades consistem em:

Acompanhar o professor na elaboração do plano de ensino, nos objetivos propostos, nas estratégias utilizadas, na seleção dos recursos.

Auxiliar no desenvolvimento das atividades de interação, no caso de EAD, na relação do professor com os alunos e dos alunos entre si.

Propor as habilidades técnicas de ensino que serão desenvolvidas na videoaula.

Realizar feedback e avaliar a videoaula.

\section{Apoio técnico}

A equipe técnica constitui-se de profissionais das área da comunicação, responsáveis pela assessoria técnica, pela gravação da videoaula. Suas principais funções são:

Assessorar o professor para o armazenamento e operação dos recursos instrucionais que serão usados na videoaula.

Auxiliar o professor para fazer a transposição do plano de ensino para o roteiro, utilizando as técnicas de comunicação.

Orientar o professor para a gravação na frente das câmeras.

Dirigir a gravação da videoaula. 


\section{Recursos instrucionais}

Os recursos instrucionais que serão utilizados e gerenciados pelo professor ficam no PC. O professor chama a atenção dos alunos para o recurso que vai ser utilizado e ele mesmo opera o PC, exibindo o recurso selecionado. Para isto, é preciso providenciar todos os recursos e armazená-los no computador numa navegação fácil e acessível para a manipulação durante a aula.

Alguns recursos podem ser usados para enriquecer a aula. São eles:

Quadro digital: uma das câmeras focará o quadro digital, no qual serão projetados os recursos, selecionados pelo professor. No caso da aula gravada, os recursos serão inseridos na edição.

Power Point: o professor poderá apresentar slides com os principais pontos de sua aula. Os slides poderão ser dinamizados com o uso do prezzi, por exemplo.

Gráficos, esquemas, resumos, desenhos: poderão ser feitos na hora da gravação da aula, usando a mesa waicon.

Animação computadorizada: a animação computadorizada poderá integrar-se com o processo de ensino-aprendizagem.

Vídeos, videoclips, mini documentários, excertos audiovisuais, takes podem estar armazenados e se constituírem em ótimos recursos de aprendizagem.

Imagens escaneadas: ilustrações, fotos podem ser escaneadas e armazenadas no PC.

\section{Tempo de duração}

Sugere-se que as videoaulas tenham a duração média de dez a quinze minutos, pois o "time" de TV é diferente do da sala de aula. Mesmo assim, é preciso que, a cada três minutos, haja um gancho de atenção para que os alunos não se dispersem do conteúdo que está sendo desenvolvido.

\section{Conteúdo}

Em relação ao conteúdo para uma videoaula, é muito importante ater-se ao seguinte:

Iniciar com uma retranca, ou seja, com o resumo do conteúdo, numa linguagem estilo manchete de jornal no tempo máximo de um minuto. 
Desenvolver a aula propriamente dita, com linguagem clara e acessível e com as inserções de recursos instrucionais.

Observação: o professor deve sentir-se à vontade, como se estivesse numa aula presencial. Trata-se de um professor e de uma videoaula e não de uma apresentação para TV ou interpretação de ator.

\section{Gravação}

A gravação de vídeo-aulas num estúdio de ensino segue a lógica da gravação de bancada do Telejornal em que são usadas três câmeras, uma para um plano aberto, enquadrando o professor em sua mesa ou em pé, outras duas cruzadas, para o corte em planos fechados e de detalhes.

\section{A Linguagem dos Planos}

Em TV, os planos podem ser fechados, médios e abertos. Nas videoaulas, os planos usados são os fechados e os médios, no caso de o professor dar a aula na mesa do professor, estando sentado. Quando o professor estiver em pé, serão utilizados planos abertos, preferindo-se o PA, Plano americano e, em alguns casos, o PG, Plano Geral para o seu enquadramento e os médios e fechados para as demais situações. A seguir, explicitam-se os planos:

Planos Fechados: são planos próximos dos objetos. São tomados a pouca distância entre a câmera e o objeto. Procuram ressaltar o ser: personagem ou objeto. Têm poder dramático e intimista. São apropriados para cenas individualizantes. São ricos em expressividade e profundidade. São muito usados em televisão, devido ao tamanho da tela. Existe a expressão que diz: "São os planos de caras e bocas". Estes planos são fundamentais para as videoaulas.

Para uma melhor compreensão, apresenta-se a nomenclatura internacional e, em seguida, a nacional.

BCU (Big Close Up): Plano de detalhe. Procura enquadrar um detalhe do rosto de uma personagem ou o detalhe de um objeto.

PPP (Primeiro Primeiríssimo Plano)

CU (Close Up): Procura enquadrar o rosto inteiro da personagem.

PP (Primeiro Plano) 

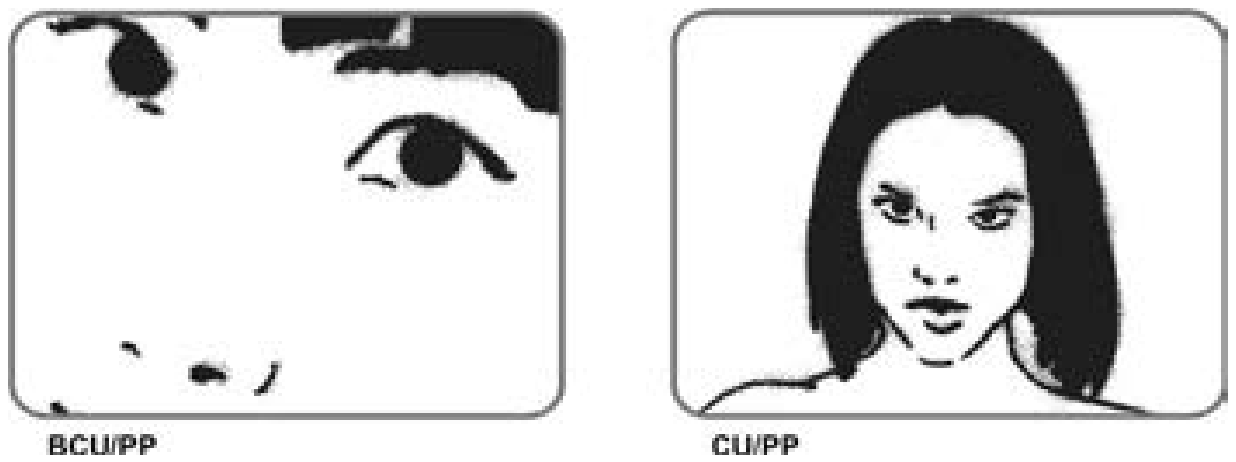

Planos Médios: são planos mais abertos do que os planos fechados. Ressaltam a pessoa da cintura para cima. São muito usados no Telejornalismo. Nas videoaulas, são essenciais, pois o enquadramento vai ser do professor sentado, quando ele estiver usando a mesa do estúdio de ensino.

MCU (Médium Close Up): Enquadrar a personagem do meio para cima.

PMF (Plano Médio Fechado)

MS (MidiumShot): Divisão da personagem do meio da cintura à cabeça. Também é conhecido como plano de cintura.

PM (Plano Médio)
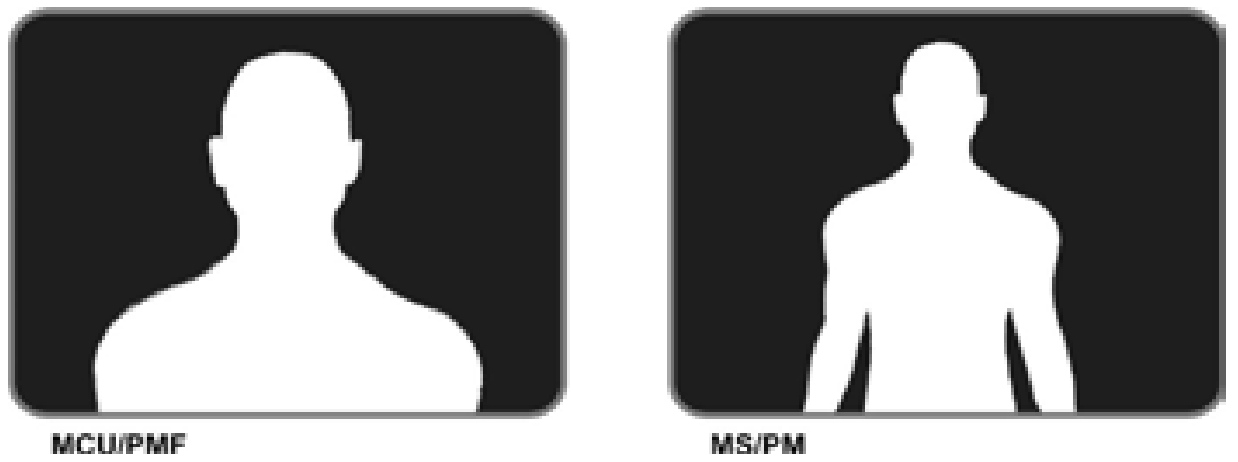

Planos Abertos: são descritivos e generalizantes; são tomadas a distância. Os planos abertos são apropriados para cenas em conjunto. São pobres em expressividade e dramaticidade. Para as videoaulas, quando o professor estiver em pé, os planos utilizados são o TS (PMA), o KS(PA), e o FS(PG). Nas vídeoaulas, são descartados os grandes planos, pois a imagens vai ficar muito longe e poluída, permitindo a dispersão dos alunos.

TS (ThigtShot): Enquadra a personagem da cabeça até a altura da coxa.

PMA (Plano Médio Aberto)

KS (KneeShot): enquadra a personagem da cabeça até o joelho. 
PA (Plano Americano)

FS (FullShot): Enquadra a personagem da cabeça aos pés. Revela o ambiente do cenário.

PG (Plano Geral)

LS (LongShot): Enquadra a personagem de corpo inteiro, ocupando 2/3 da altura do vídeo. Sobra $1 / 3$ de teto acima da cabeça da personagem.

GP (Grande Plano)

ELS (Extreme LongShot): procura ressaltar todo o ambiente. A personagem está perdida no ambiente.

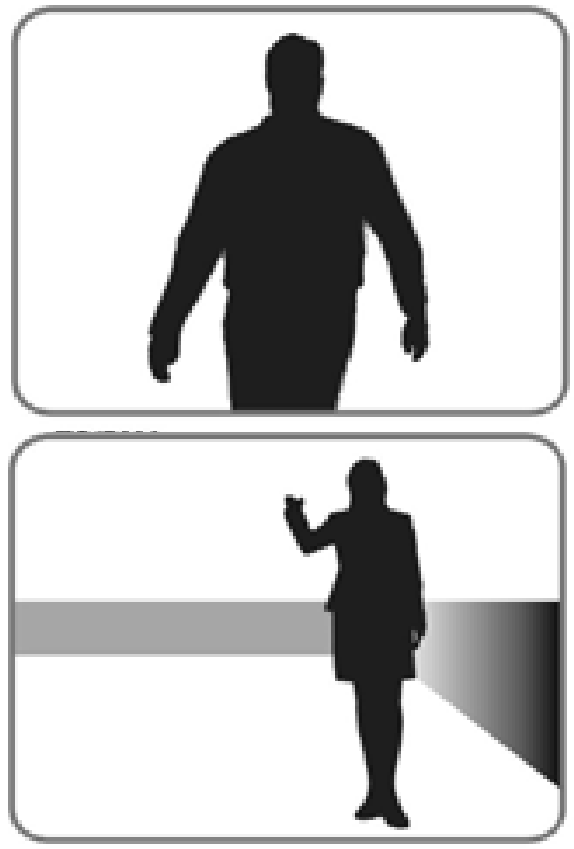

FS/PG
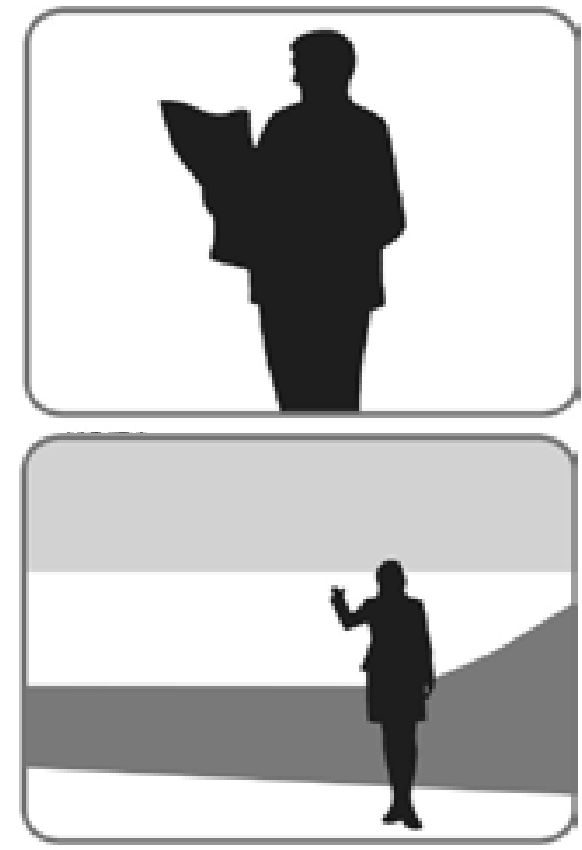

LSIGP

Numa nomenclatura mais usual, os planos são divididos em planos de detalhe, quando a câmera fecha o enquadramento em um detalhe do objeto ou personagem, close, rosto da pessoa, planos médios, do peito e da cintura para cima da personagem e planos abertos, do meio da coxa para cima, plano americano e enquadrando o corpo todo. Para a gravação de uma vídeo-aula, há necessidade de uma equipe, constituída pelos operadores de câmera, um switcher, para realizar os cortes e um diretor técnico.

\section{Dicas para uma boa apresentação na vídeo-aula}

É preciso considerar que se trata de uma aula e não de uma apresentação de programa de TV. Portanto, quem ministra a aula é um professor e ele deve ser 
o mais natural possível, como se estivesse na frente dos seus alunos. Aconselhase que o professor fale com naturalidade e que não utilize recursos de leitura como TP (teleprompter), pois isto torna a aula artificial e dificulta a utilização das habilidades técnicas de ensino.

A equipe de comunicação será responsável pela orientação dos professores. As dicas principais são:

Ter uma boa postura, ajustando-se aos enquadramentos e planos.

Relaxar e respirar diafragmaticamente.

Transmitir a sensação de calma, tranquilidade, segurança e confiança.

Ficar à vontade no estúdio, esquecendo-se de que as câmeras existem.

Colocar os apontamentos ao alcance da mão ou no TP.

\section{Cuidados com a aparência}

Como se trata de um professor dando uma aula, sugere-se que ele seja ele mesmo, que não busque padrões que não o identifiquem e que dispersem os alunos.

Simplicidade: ter o cuidado de não poluir a cena com acessórios, cores e padrões.

Bom senso: ter critério, para escolher o que usar.

Elegância: adequar-se ao que se é, ao que se faz e onde se está.

Modismo: ser atual, ser fiel a uma maneira de ser, evitando modismos e extrapolação ao novo.

Racionalidade: ser racional nas escolhas, pois a roupa define, muitas vezes, a cultura, o gênero e a religião. É preciso ter cuidado com o que se quer expor.

\section{Cuidados com a roupa}

Adequada: estar adequada à pessoa e à situação.

Confortável: ser confortável, permitindo movimentos naturais.

Tamanho: estar de acordo com o tamanho da pessoa.

Cores: combinar cores, matizando, para atenuar contrastes.

Branco: deve ser evitado, pois amplia, engorda e deixa a imagem com reflexos.

Listras e Xadrezes: devem ser evitados, pois causam batimentos no vídeo, ou seja, deficiência da imagem.

Estampas: evitar, pois poluem o cenário. 


\section{Cuidados com os acessórios}

Óculos: preferir lentes anti-reflexo, evitar armações metalizadas.

Adornos: evitar, pois distraem e refletem com a iluminação.

Lenços: se usados, discretos e opacos.

\section{Cuidados com o cabelo (professoras)}

Os curtos não chamam a atenção.

É importante manter o corte.

Evitar os cabelos volumosos, pois ocupam toda a tela.

Cabelos longos: quando longos, os cabelos devem estar assentados.

\section{Cuidados com a maquilagem}

O pó tira o excesso de oleosidade, evitando o brilho da pele.

O pó facial pode ser usado nos professores, principalmente em entradas e carecas, pois evita o brilho.

A pintura deve ser discreta. Se bem usada, ela realça os olhos e a boca. Ela atenua as marcas de expressão, os contornos do nariz e disfarça as olheiras.

\section{Considerações conclusivas}

Com a expansão da EAD, a Internet tornou-se um veículo para a postagem de vídeo aulas e webaulas quer sejam elas gratuitas ou não. Estas vídeo-aulas e web-aulas apresentam, geralmente, o professor na frente de uma lousa, convencional ou digital, dando a sua aula, ou mesmo em off com animações e exercícios na tela do computador.

Em relação aos planos, as videoaulas disponíveis na web mostram o professor, normalmente, em plano americano, de costas, voltado para a lousa, na maioria das vezes lousa verde, onde ele escreve com giz. Quando o professor utiliza recursos, ele divide a tela com os mesmos e, em alguns momentos, não entra em quadro, pois utiliza as ilustrações e os desenhos, explicando-os em off.

A web apresenta uma quantidade considerável de vídeo-aulas e de webaulas, muitas delas podendo ser acessadas gratuitamente. Neste segmento, encontram-se as videoaulas de Matemática da Khan Academy, apresentadas em torno de 10 minutos por Salman Khan com linguagem clara e objetiva. Com o sucesso da Khan Academy, as aulas foram traduzidas para diversas línguas e 
ampliadas para outras áreas do conhecimento como física, química, biologia, etc.

A partir de 2009, o youtube criou um link, youtube/edu, reunindo material educativo das mais variadas áreas. Com isso, é possível ter acesso gratuito a vídeo e web-aulas, para serem usadas tanto em ensino semi-presencial como em EAD. A partir de tais considerações, justifica-se a produção de vídeo e web-aulas, gravadas com os recursos de um estúdio de ensino, tornando-as cada vez mais qualificadas e destinadas a processos específicos de ensino e aprendizagem dos mais variados tipos de curso e/ou formação.

É preciso, portanto, conhecer a linguagem audiovisual e buscar a tecnologia do vídeo para, cada vez mais, tornar as aulas de EAD dinâmicas e interessantes, compatíveis com os objetivos que se quer atingir. Apesar de ser introduzido no Brasil na década de 60, o microensino e as habilidades técnicas do professor permanecem até hoje contribuindo para a formação e a capacitação docente nos mais variados níveis.

Acredita-se que, utilizando as habilidades técnicas de ensino e integrandoas à tecnologia de um estúdio de ensino, é possível contribuir com a formação docente e com a educação continuada, buscando qualificar a sala de aula com o uso das tecnologias disponíveis.

\section{Referências}

ALLEN, D. W.; WAI-PING, W. Micro-teaching. Beijing: HsinHuaPublishers, 1996. Disponível em: <htpp:///www.in.edu.tcl/learning matters/01-99-30\%> Acesso em: 11 mar. 2008.

BAPTISTA, M., QUARESMA, M., MATA-PEREIRA, J.,\& PONTE, J. P. (2014 janeiro 24). Os estudos de aula como contexto de desenvolvimento profissional. Comunicação apresentada no Seminário "Práticas profissionais: Desafios para a Formação de Professores de Matemática" organizado pelo Projeto P3M, Instituto de Educação da Universidade de Lisboa.

CARRAVETTA, Luiza Maria Cezar. Construindo o Telejornal. Porto Alegre: Armazém Digital, 2009.

CARRAVETTA, Luiza Maria Cezar e COELHO, Marta de Moraes. O Vídeo Educativo, Uma Ferramenta para o professor. Porto Alegre: Algo Mais, 2010.

CUSTÓDIO, José de Arimathéia Cordeiro. Diálogo e Interação. Volume 3, 2010. Disponível em: < $\underline{\text { http//www.faccrei.edu.br/dialogoeinteracao }>}$

DONÁ HILA, Cláudia Valéria. Acta Scientiarumand Social Sciences. Vol 31, n 1, 2009. 
Félix, T. (2010). Pesquisando a melhoria de aulas de Matemática seguindo a proposta curricular do estado de São Paulo, com a metodologia da pesquisa de aulas (lessonstudy) (Tese de Mestrado). Universidade Federal de São Carlos, São Carlos p.33-41.

MORAN, José Manuel. Aperfeiçoando os modelos de EAD existentes na formação de professores. Educação. Porto Alegre, v.32, n.3, set./dez. 2009. p.286-290.

SANT'ANNA, Flávia Maria. Microensino e Habilidades Técnicas do Professor. São Paulo: McGraw-Hill do Brasil, 1979.

Recebido em: 10 janeiro 2015

Aceito em: 12 março 2015

Endereço do autora:

Luiza Carravetta < carravetta@unisinos.br>

Universidade do Vale dos Sinos

Escola da Indústria Criativa

Avenida da Unisinos, 950. Bairro Cristo Rei.

Cep 93022-000

Cidade: São Leopoldo/RS

Fone: (51) 3591-1122 